\title{
Effects of exploratory learning on Breakthrough Innovation, Knowledge spiral as Mediator
}

\author{
Ming-Lin Zhang \\ Regional innovation and entrepreneurship research center, \\ Business School, \\ Jiangxi Normal University, \\ Jiangxi, China \\ E-mail: mlzhang03@163.com
}

\author{
Li-Qing Wen \\ Business School, \\ Jiangxi Normal University, \\ Jiangxi, China \\ E-mail: 1084764892@qq.com
}

\begin{abstract}
Breakthrough innovation is not only an effective way to achieve a technological leap, but also increasingly becoming an important means for enterprises to achieve latecomer to catch up, maintaining a sustained competitive advantage, becoming the focus of enterprises to develop industrial policies and development strategies of attention. In this paper, methods of structural equation, exploratory research study on the impact of breakthrough innovation mechanisms and knowledge spiral as Mediator, the study "Exploring Learning $\rightarrow$ knowledge spiral $\rightarrow$ breakthrough innovation," the effect of this path.
\end{abstract}

Keywords-Exploring learning, Breakthrough innovation, Knowledge spiral, SEM

\section{INTRODUCTION}

Improve the capability of independent innovation, strengthen scientific and technological innovation is the driving force of the economy China's "Twelfth Five-Year Plan" of the strategic plan. There are very much literature on business breakthrough innovations influencing mechanism by Domestic and foreign scholars. As Atua-hene-Gima (2007) believes that exploratory learning can help companies acquire existing capacity quite different skills and knowledge, but at the same time reducing the concerns of existing capacity, which is conducive to breakthrough innovation to the detriment of progressive innovation. Xiao-Hui Yang (2011) from the disruptive technology innovation capability of knowledge common view, that it is the companies rely on innovation breakthrough technology to improve the level of knowledge, beyond the ability of enterprises to promote development. So, to say researches breakthrough innovation enterprise focused on several aspects: First, knowledge conversion, dynamic environment of technological innovation capacity, made a number of classic models. Second, the impact of corporate social capital within and outside of disruptive technology innovation, mainly from the structural dimension, cognitive dimension and relational dimension analysis of enterprise knowledge management and technological innovation.

However, existing research has not yet been exploratory learning on breakthrough innovation conduct in-depth research, the study will explore the specific dimensions of the relationship between research and breakthrough innovation is also less, but also not considered the need for knowledge spiral as an intermediary variable. This obviously can not fully reveal the mechanisms of exploring learning ways to influence. In response to these deficiencies, learn from existing research results, this paper on the basis of exploratory learning and breakthrough innovation performance on the theoretical analysis, conceptual model to build Spiral mediating effect of knowledge, to enrich learning, knowledge management and enterprise theory of breakthrough innovation theory, provide guidance and advice to innovative management practices of enterprises.

\section{LITERATURE REVIEW AND RESEARCH HYPOTHESES}

\section{A. Literature Review}

\section{1) Exploratory learning}

Learning refers to the organization has the ability, technology and paradigms such as refining and expanding exploratory study refers to the organization of new knowledge, new technology, etc. Atuahene \& Gima (2007) believes that exploratory learning can help companies acquire existing capacity quite different skills and knowledge, but at the same time reducing the concerns of existing capacity, which is conducive to breakthrough innovation to the detriment of incremental innovation . Yang Xidong(2010) study exploratory learning are: to enable enterprises to focus on collecting new things to learn the art of information; focus on understanding business is temporarily not be applied to new knowledge and new method; focus on the market demand but temporarily known related technologies of new products; and market-oriented collection contains technical information and test high-risk; focus on learning experience beyond the company's current technology.

\section{2) Knowledge Spiral}

Michael Polanyi (1958) was confirmed from the field of philosophy of "tacit knowledge" and "explicit knowledge" category, tacit knowledge refers to the particular environment-related personal knowledge, personal experience and intuition belongs to, it is difficult to formalize and forms oriented, and difficult to communicate. In a highly competitive environment, the conduct of this enterprise is the 
accumulation and transformation of the organization and use of tacit knowledge, only the tacit knowledge that has the originality and easy imitative.

\section{3) Radical Innovation}

Christensen (1997) based on the trajectory of technological innovation differences, differences in the degree of innovation, innovative ways differences, differences in the target market, the technological innovation is divided into two incremental technology innovation and breakthrough technology innovation types...Li Honggui, Xiong Shengxu (2010) pointed out that disruptive technology innovation to try to tap the tacit knowledge, technology trend analysis, evaluation of the value of knowledge, and then use the knowledge to design product model, through advertising and other media to promote its new technology and new product phases.

\section{B. Hypothesis}

1) The relationship between exploratory learning and breakthrough innovation

What is the relationship between exploratory learning and breakthrough innovation in end? Scholars are discussed. From the literature, we know exploratory learning can help companies effectively search, identification and tracking of new technologies in the field of knowledge, and promote scientific innovation model and management model, thereby existing target market and where the industry to re-create subversive. Based on the above analysis, we can assume that:

$\mathrm{H} 1$ : exploratory learning on radical innovation can promote.

2) The relationship between exploring learning and knowledge spiral

Currently, some scholars have proposed exploratory learning is through effective enterprise search, identification and tracking of new technologies in the field of knowledge, and the dissemination of knowledge to this invisible corporate executives, by consensus, to achieve knowledge spiral "in common"; Enterprise High tube through continuous exploration and learning, which summarizes new conclusions, thereby notifying the entire company to achieve knowledge spiral "externalization". It is because of corporate executives and grassroots continue to explore learning in order to achieve the organization of "knowledge spiral." Therefore, we assume that: spiral.

$\mathrm{H} 2$ : exploratory learning can promote the knowledge

3) The relationship between knowledge spiral and breakthrough innovation

Breakthrough Innovation must first try to tap the tacit knowledge, analysis technology trend, evaluation of knowledge value. Tacit knowledge in the excavation process, corporate executives through study and discussion, further hidden knowledge into explicit knowledge, enabling knowledge "in common". Therefore, breakthrough innovation process is inseparable from the enterprise business process knowledge spiral. Therefore, we can assume:

H3: Knowledge Spiral enterprises can promote radical innovation.

\section{4) Mediating Role of Knowledge Spiral}

Based on the above analysis, we have come: exploratory learning promote the knowledge spiral while knowledge spiral can promote enterprise breakthrough innovation. Therefore, we can assume:

H4: Knowledge spiral play an intermediary effect in exploratory learning on breakthrough innovation.

Thus, we can build a relationship between exploratory learning, knowledge spiral and breakthrough innovation model shown in Figure.1.

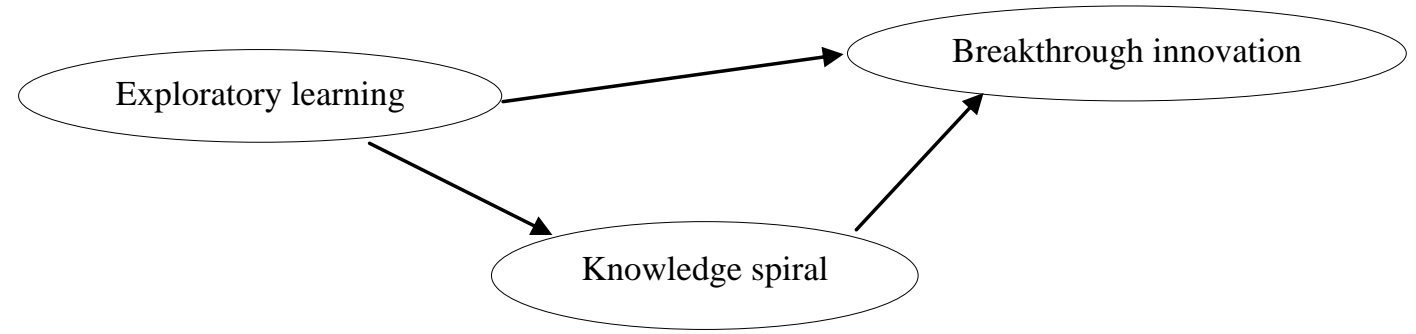

Figure 1 The relationship between exploratory learning model, knowledge spiral and Radical Innovation

\section{RESEARCH DESIGN}

\section{A. Metric variable}

\section{1) Exploratory learning}

Measuring exploratory learning the main reference Yang Xidong (2010) research, measurement indicators exploratory learning are: enterprises focus on gathering information to learn the new things (EL1); focus on understanding business is applied to new knowledge and new methods (EL2); pay attention to the market demand but related technologies to new products (EL3); focus on learning experience beyond the company's current technology (EL4).

\section{2) Knowledge Spiral}

Knowledge Spiral Nonaka main reference variables measured such questions of measurement scale, the scale of the development, design questions of the7, KS1- companies often acquire information and sharing of experience from sales and production sites; KS2-companies often expand the" brainstorming "; KS3- enterprises have sound expertise manuals; KS4- enterprises establish a rich database of products and services; KS5- companies have a wealth of 
information, learning the course and practice experience knowledge base; KS6- companies often intersectoral job training; KS7- companies often organize employees face to face to discuss the success Stories.

\section{3) Breakthrough Innovation}

Qin Jian (2010) and Yin Huibin (2014) studied the Breakthrough Innovation Performance Evaluation System, and breakthrough innovation performance (BI) target setting measure to: BI1- often create new products to improve performance, not style or other aspects of the service, and sales in the market; BI2- creation of a new technology, not an existing process improvements.

4) Control variable

In this study, firm size, business ownership, which the industry as a control variable.

\section{B. Sample selection}

This study used survey questionnaire with Likert scale method five, 5 stands strongly agree, 1 for strongly disagree. First, the research team conducted in MBA class students in pre-research, conducted on a small sample recovery test reliability and validity and content of amendments to finalize the contents of the questionnaire. 2016 March-May, the City of Jiangxi Province High-tech Development Zone, a large-scale survey, 120 questionnaires were distributed to recover 104 parts, excluding the answer is incomplete or obviously erroneous questionnaire 8 parts, 96 parts of valid questionnaires, effective response rate was $80 \%$.

\section{Empirical analysis}

\section{1) Variable reliability and validity analysis}

In this study SPSS21.0 software, using exploratory factor analysis (characteristic root> 1) of the questions of the variables to analyze and extract common factor. First exploratory learning scale principal component analysis and orthogonal rotation to give two common factors EL4 and EL3, cumulative variance contribution rate of 72.440, KMO value of 0.677 , Bartlett is 31.587 (sig. $=0.000$ ). Using the same method of extracting knowledge from the spiral scale to three common factors KS4, KS3and KS6, cumulative variance contribution rate of $78.173, \mathrm{KMO}$ value of 0.710 , Bartlett is 145.832 ( $\mathrm{sig}=0.000$.); From breakthrough innovation performance scale extracted to a common factor $\mathrm{BI}$, cumulative variance contribution rate of 56.913, KMO value of 0.533 , Bartlett is 28.621 ( $\mathrm{sig}=0.000$.); reliability and validity of the test results shown in table 1 scale.

TABLE I. VARIABLE RELIABILITY AND VALIDITY OF TEST RESULTS

\begin{tabular}{|c|c|c|c|c|c|}
\hline variable & Questions & Load factor & variable & Questions & Load factor \\
\hline \multirow{4}{*}{$\begin{array}{l}\text { Exploratory } \\
\text { learning }\end{array}$} & EL1 & 0.729 & \multirow{7}{*}{$\begin{array}{l}\text { Knowledge } \\
\text { Spiral }\end{array}$} & KS1 & 0.778 \\
\hline & EL2 & .485 & & KS2 & 0.762 \\
\hline & EL3 & 0.568 & & KS3 & 0.790 \\
\hline & EL4 & 0.636 & & KS4 & 0.814 \\
\hline \multirow{3}{*}{$\begin{array}{l}\text { Breakthrough } \\
\text { Innovation }\end{array}$} & BI1 & 0.719 & & KS5 & 0.790 \\
\hline & \multirow{2}{*}{ BI2 } & \multirow{2}{*}{0.725} & & KS6 & 0.707 \\
\hline & & & & KS7 & 0.532 \\
\hline
\end{tabular}

As we can see from the above analysis, the cumulative contribution rate of each common factor of more than $70 \%$, indicating the scale has good content validity and construct validity; Cronbach's $\alpha$ value of 0.911 , based on standardized items Cronbach's $\alpha$ is 0.911 , and both above 0.8 , indicating good internal consistency reliability scale.

\section{2) Variable descriptive statistics}

Scale by descriptive statistical analysis of data, obtained variables Pearson coefficient, the mean and standard deviation are shown below.

TABLE II.VARIABLE COEFFICIENT PEARSON

\begin{tabular}{|c|c|c|c|c|c|c|c|c|c|}
\hline & EL1 & EL2 & EL3 & EL4 & KS3 & KS4 & KS6 & KS7 & BI2 \\
\hline EL1 & 1 & & & & & & & & \\
\hline EL2 & $.510 * *$ & 1 & & & & & & & \\
\hline EL3 & $.431 *$ & .249 & 1 & & & & & & \\
\hline EL4 & $.476 * *$ & .255 & $.728 * *$ & 1 & & & & & \\
\hline KS3 & $.454 *$ & .224 & .289 & .204 & 1 & & & & \\
\hline KS4 & $.564 * *$ & .344 & $.383^{*}$ & $.391 *$ & $.737 * *$ & 1 & & & \\
\hline KS6 & $.372 *$ & .078 & .166 & .262 & $.719 * *$ & $.793 * *$ & 1 & & \\
\hline KS7 & .182 & .139 & .173 & .164 & $.579 * *$ & $.400 *$ & $.488 * *$ & 1 & \\
\hline $\mathrm{BI} 2$ & $.404 *$ & $.441 *$ & $.450^{*}$ & $.480 * *$ & $.623^{* *} *$ & $.455 *$ & $.378 *$ & $.620 * *$ & 1 \\
\hline
\end{tabular}

** In the .01 level (one-sided) significant correlation. * At the 0.05 level (one-sided) significant correlation.

\section{3) Mediating variables inspection}

Through the above analysis, testing knowledge spiral intermediary role, follow these steps:
Step One: an exploratory learning $\rightarrow$ breakthrough innovation

Step Two: exploring learning $\rightarrow$ knowledge spiral 
Step Three: exploring learning, knowledge spiral $\rightarrow$ breakthrough innovation

\section{REGRESSION RESULTS}

Regression Analysis:

TABLE III.

Intermediary knowledge spiral test results

\begin{tabular}{|c|c|c|c|c|c|c|}
\hline & \multicolumn{2}{|c|}{ Model1 } & \multicolumn{2}{|c|}{ Model2 } & \multicolumn{2}{|c|}{ Model3 } \\
\hline & $\beta$ & $\mathbf{T}$ & $\beta$ & $\mathbf{T}$ & $\beta$ & $\mathbf{T}$ \\
\hline EL1 & .088 & .557 & .147 & 1.038 & -.021 & -.172 \\
\hline EL2 & .406 & 3.364 & .246 & 2.271 & .225 & 2.401 \\
\hline EL3 & .190 & 1.432 & .150 & 1.263 & .079 & .783 \\
\hline EL4 & 249 & 1.993 & .015 & .137 & .237 & 2.524 \\
\hline $\mathbf{K S}$ & & & & & .738 & 8.337 \\
\hline R2 & \multicolumn{2}{|c|}{0.604} & \multicolumn{2}{|c|}{0.528} & \multicolumn{2}{|c|}{0.802} \\
\hline $\mathbf{F}$ & \multicolumn{2}{|c|}{10.329} & \multicolumn{2}{|c|}{26.744} & \multicolumn{2}{|c|}{40.926} \\
\hline
\end{tabular}

We analyze the effect of mediation by Sobel test.

From the table, in the Model1, T (EL2) $=-3.364, \mathrm{~T}$ (EL4) $=1.993$, greater than 1.96, EL2 and EL4 are significant. In Model2, we simply check EL2 and EL5 significance, found that only $\mathrm{T}(\mathrm{EL} 2)=2.271>1.96$, and $\mathrm{T}(\mathrm{EL} 4)=0.137<1.96$. In the Model3, T $(E L 4)=2.524>1.96$, is significant, T (EL2) $=2.401>1.96$ significant. In the Model3, $\mathrm{T}(\mathrm{KS} 7)=8.337$, is remarkable.

In summary, for EL2, Model2 significant factor in EL2, Model3 significant factor in KS7, EL2 coefficient significantly, so KS7 mediating effect between EL2 and BI2 significant.

About the size of an intermediary role, Mode 11 is the total effect, Model3 direct effect, the size of the mediating effect of:
Mediating Effects $=0.406-0.225=0.181$

Or mediating effect $=0.738 * 0.246=0.181$

For EL4, in Model 2 in EL4 coefficient is not significant, Model3 significant factor in KS7, so we need to do Sobel test.

$$
\mathrm{s}=\left(0.015^{\wedge} 2 * 0.000^{\wedge} 2+0.738^{\wedge} 2 * 0.399^{\wedge} 2\right) 1 / 2=
$$
0.294

$\mathrm{Z}=-0.015 * 0.738 / 0.294=0.038<0.05$, significant

So, KS7 mediating effect between EL4 and BI2 significant.

\section{STRUCTURE OF THE ROAD MAP}

Use AMOS17.0 get exploratory learning, knowledge spiral road map, breakthrough innovation is as follows:

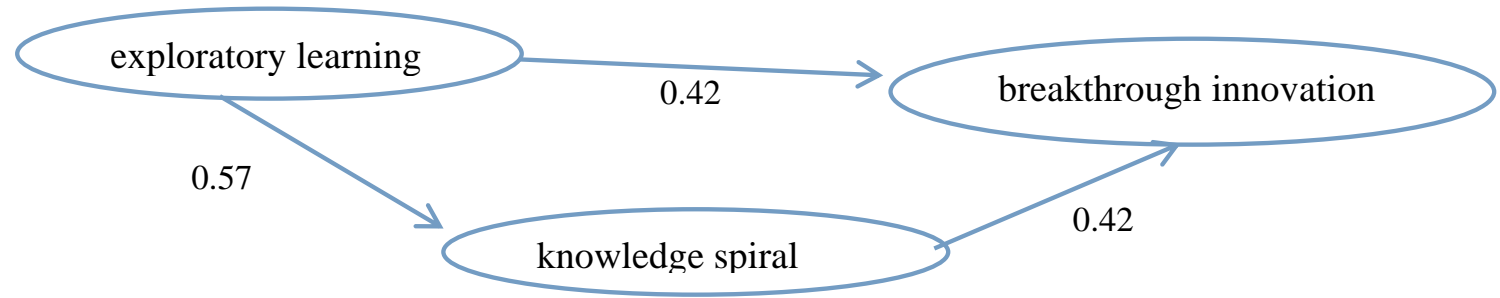

Figure 2 Structure of the road map

In the path model, the $\mathrm{P}$ value of less than 0.05 indicates significant. The path model $\mathrm{P}$ values were less than 0.05 , indicating a reasonable path, which exist more than one path to explore the relationship between learning, knowledge spiral, and breakthrough innovations.

\section{CONCLUSIONS AND IMPLICATIONS}

\section{A. Analysis of findings}

Combination of the above analysis, we can find: "exploratory learning $\rightarrow$ knowledge spiral $\rightarrow$ breakthrough innovation," the path has been verified. That exploratory learning by influencing corporate explicit knowledge and tacit knowledge to affect breakthrough innovations.

\section{B. policy suggestion}

1) Actively guide enterprises exploratory learning

In general, companies often strive to exceed our competitors in terms of cost and quality. In this case companies will form a fixed thinking, Hinder breakthrough innovations, Enterprises should break the fixed mode of thinking. This requires enterprises to continuously learn, especially now that the context of information technology, to do better than others, but also need to constantly exploratory learning. In this present era of knowledge economy, the needs of enterprises through continuous exploration learning to expand organizational capabilities, in addition to the accumulation of new knowledge beyond the existing technology. 
2) Enhance knowledge resources and capacity utilization

Being able to search for knowledge and innovation signals effectively identify, seize opportunities for innovation. Is access to knowledge resources for the realization of innovation activities of enterprises taken?

3) Strengthen internal communication

Internal communication to ensure the dissemination of explicit knowledge and tacit knowledge within the enterprise to achieve knowledge and information sharing, based on existing knowledge, it can help enterprises make the right decisions, and achieve breakthrough innovation.

\section{ACKNOWLEDGEMENT}

This research was financially supported by the Graduate Innovative Foundation and the Jiangxi Normal Universities young teachers visiting scholar development plan special funds.

\section{REFERENCES}

[1] Nonaka,Toyama,R.\&Konno, N, "SECI, Ba and leadership: a unified model of dynamic knowledge creation", Long Range Plaiming, vol.33, pp.205-260, 2000.

[2] Faems\&Debackere,K, "Interorganizational collaboration and innovation:Toward a Portfolio approach", Journal of Product Innovation Management,vol.22,pp.238-250, Mar. 2005.

[3] Atuahene-Gima,K., "Resolving the capability-rigidity Paradox in new Product innovation", Journal of Marketing,vol.69,pp.61-83, Apr. 2005.

[4] Yang Xidong, "strategic orientation, organizational learning on product innovation research", Management Review, vol22, pp.47-55, Apr. 2010.

[5] Yin Huibin, You Daming, Liu Haiyun, "Moderating Effect of Environmental Dynamism on exploratory learning and Radical Innovation Performance", East China Economic Management, pp. 107-112, Aug. 2014.

[6] Zhu Siwen, "A study on the breakthrough technology innovation capability of tacit knowledge absorption". Central South University, 2013. 